WHOLE bacteria or bacterial components or their extracts were employed to restore or augment the immune system. Beneficial effects were attained with these agents in treating various diseases. These agents were named biological response modifiers (BRMs) because they regulated certain cellular components of the immune system. The cellular regulation induced by these BRMs was found to be due to cytokines. The cytokines were shown to act directly on the various cellular components and to provide therapeutic benefit in various autoimmune and immune deficiency diseases. Overproduction of specific cytokines however leads to a deleterious effect on the host. Overproduction of tumour necrosis factor (endotoxin, lipopolysaccharide) leads to septic shock. Bacteraemia is the leading cause of overproduction of tumour necrosis factor (TNF). Septic shock in many cases leads to death. Several monoclonal antibodies to lipopolysaccharide (LPS) and anticytokines have demonstrated protection against septic shock.

Key words: Biological response modifiers, Cytokines, Interleukins, Septic shock, Tumour necrosis factor

\section{Immunoregulatory biological response modifiers: effect of cytokines on septic shock}

\author{
Michael A. Chirigos ${ }^{1, C A}$ and \\ Claudio De Simone ${ }^{2}$
}

National Cancer Institute, National Institute of Health, Bethesda, MD, USA; ${ }^{2}$ Infectious Diseases, Department of Internal Medicine, University of L'Aquila, L'Aquila, Italy

\author{
${ }^{\mathrm{C}}$ Corresponding Author; 4 Cold Spring Court, \\ Potomac, MD20854, USA
}

A little over 25 years ago the concept of introducing an exogeneous substance to elicit a host immune response was limited to such agents as bacterial organisms (Table 1), to be followed a few years later by the use of partially purified microbial extracts or fractions (Table 2). The use of these microbial agents to stimulate the immune response gave way to the use of chemically defined BRMs (Table 3), and to extracts from yeast, fungi, plants and herbs ('Table 4), and polysaccharides ('Table 5). ${ }^{1,2}$

During the past 15 years, as the result of progress made in molecular biology, the immunoregulating effects attributed to the aforementioned BRMs were found to be due to cytokines that were induced and secreted by cells responding to these BRMs (Table 6).

The capacity of several of these BRMs to regulate a specific cell population and/or induce the production of a specific cytokine and its therapeutic

Table 1. Biological response modifiers of biological origin

Microorganisms (bacterial preparations)

Bacillus Calmette-Guerin (BCG) Corynebacterium parvum

Brucella abortus

Bordetella pertussis

Nocardia rubra

Pseudomonas aeruginosa

Chlorella vulgaris

Klebsiella pneumonia

Diplococcus pneumonia

Haemophilus influenza Streptococcus pyogenes

$S$. aureus, S. viridans

Neisseria catarrhalis

Salmonella typhimurium

Listeria moocytogenes

Streptomyces folvoviridis

Serratia marcescen

Chlorella vulgaris use for various diseases is shown in Tables 7 to 11 Table 7 shows that the use of BCG increased the various cellular responses: T-cells, macrophages (MPG), natural killer cells (NK), and cytotoxic T-lymphocytes (CTL). The cytokines induced by BCG are interleukin 1 (IL-1), IL-2, interferon alpha (IFN- $\alpha$ ), granulocyte monocyte colony stimulating factor (GM-CSF), and tumour necrosis factor (TNF). Treatment with BCG alone, or combined with other treatment modalities (chemotherapy, surgery, irradiation), resulted in beneficial responses in several animal and human cancers. BCG

Table 2. Biological response modifiers of biological origin

Microorganisms (complete or partially pure extracts)

Picibanil (OK432, Streptococcus pyogenes)

MER (methanol extracted residue, BCG)

MY-1 (extract BCG)

RU41740 (Biostim, glycoprotein, K. pneumoniae)

Mycolic acid (glycolipid, Nocardia rubra)

Bru Pel (Brucell abortus)

MDP (muramyl dipeptide, Mycobacterium smegmatis)

WSA (disaccharide peptoglycan, Mycobacterium smegmatis)

CWS (cell wall skeleton, BCG, Nocardia rubra)

Forphenicino 1 (Aspergillus fulvoviridis)

GBA (amino sugar polymer, cytophaga)

BV (Broncho Vaxom, alkaline lysis extract of eight bacterial mixtures)

Imuvert (ribomes and membrane vesicles of Serratia marcescens) Detox (detoxified endotoxin)

OM-89 (purified E. coli extract)

C.VE (glycoprotein, $\mathrm{H}_{2} \mathrm{O}$ extract of Chlorella vulgaris)

SSG ( $\beta$ 1,3 glucan, Sclerotinia sclerotiorum)

Other fungal extracted $\beta$ 1,3 glucans (sonifilan, sizofiran, grifolan) 
Table 3. Chemically defined biological response modifiers

\begin{tabular}{lll}
\hline Amphotericin B & HAB 439 & Splenopentin (DAcSP-5) \\
Azimexon & Imuthiol & SPG \\
ADA 202-718 & Indomethacin & THFy 2 \\
ABPP & Isoprinosine & TOK 8801 \\
A 171-172 & LF 1695 & Thymopentin \\
Bestatin & L 646,257 & Tuftsin \\
Betafectin & Levamisole & Therafectin (SM 1213) \\
Cimetidine & Lipidal amines & Thiazolobenzimidazole \\
CL 246,738 & MDPs & Thiobendazole \\
CL 259,763 & MPG & IFN inducers: \\
DT 5461 & MIMP & Poly IC \\
EL-1, EL-2 & Pyrimidinols & Poly ICLC \\
Formosanin-C & Retinoids & Poly AV \\
Forphenicinol & Ricin & Ampligen \\
FK 506, FK 565, & SM 8849 & Anthroquinones \\
FK 156 & SDZ MRL 953 & RP 40639 Pimelantide \\
RU 41740 (Biostim) & Oxamisole & \\
\hline
\end{tabular}

treatment of human transitional cell carcinoma of the bladder led to greater than $90 \%$ regression with minimal recurrence. More recently local/regional immunotherapy with IL-2 was reported to also mediate regression of this tumour type. ${ }^{3}$ This response demonstrates that the cytokine inducer (BCG), as well as the BCG induced cytokine (IL-2) were both therapeutically effective against the same tumour.

OK 432 ('Table 7) has had extensive preclinical and clinical evaluation ${ }^{4-6}$ and has been shown to be beneficial in treating various cancers. Similarly, Lentinan has shown efficacy in augmenting immune restorative activity beneficial for treating various infections. ${ }^{4}$ Tables 8 to 11 describe several BRMs of bacterial, thymus, and polysaccharide origin which exert immunoregulatory activity.

Swainsonine (Table 11) was recently reported to cause a marked elevation in superoxide radical

Table 4. Extracts from yeast, fungi, plants and herbs

\section{Extracts isolated from yeast or fungi}

Krestin (PSK, protein bound polysaccharide, Coriolas versicolor) Glucan (beta 1,3 polyglucose, Saccharomyces cerevisiae)

Lentinan (beta 1,3 polyglucose, Lentinus edodes)

Cyclomunine (cyclohexa peptide, Fusarium equiseti)

Bestatin (2S, 3R-amino-2-hydroxy-4-phenylbutanoyl-L-leucine, Streptomyces olivoreticuli)

Schizophyllan (beta 1,3 polyglucose, Schizophyllum commune) SPG (sulphated schizophyllan)

FK156 and FK565 (tetrapeptides, Streptomyces olivaceogriseus)

AM-3 (protein complexed beta 1,6 polyglucan, Candida utilis)

\section{Plant and herb extracts}

Ace mannan (Carrisyn, Aloe vera barbadensis)

Bryostatin (macrocyclic lactones, marine plant Bryozoan bugula meritina)

RBS (RON) ( $\alpha$-glucan derived from rice bran)

Formosanin-C (diosgenin saponin, Paris formosana hayata plant, Liliaceae)

Ginseng (Panax ginseng, Araliaceae)

Huang-chi (Astragalus membranaceus, Leguminosae)

Shosaiko-To (Xiao-Chai-Hu-Tang, seven herb mixture)
Table 5. Polysaccharide biological response modifiers

AM3

$\beta-1,6$, polyglycan protein

(Candida albicans)

Betafectin

poly $(1,6) \beta$-D-glycopyranosyl-(1,3) $\beta$-D-glucopyranose

(Saccharomyces cerevisiae)

Curdlan sulphate (CS)

sulphated $\beta$-1, 3-D-glucopyranan

Glucan

$\beta-1,3$ glucose

(Saccharomyces cerevisiae)

GBA

$N$-acetyl glucosamine

(Cytophaga bacterium)

Lentinan

$\beta$-1,3-glucan, 1 -6- $\beta$-D glucopyranoside

(Lentinus edodes, mushroom)

PSK (Krestin)

protein bound polysaccharide

(Coriolus vesicolor, mushroom)

RBS (RON)

$\alpha$ glucan

derived from rice bran

RU41740 (Biostim)-MPG

glycoprotein extract

(Klebsiella pneumoniae)

\section{SDZ MEL 953}

synthetic acylated glucosamine-monosaccharide-1- $\mathrm{PO}_{4}$

SSG

$\beta-1,3$ D glucan

(Sclerotinia sclerotioram, fungus)

Sizofiran

$\beta$-polyglucan

(Schizophylum commune)

SPG

$\beta-1,3$ glucan

(Sulphated Schizophylum)

Sonifilan

$\beta-1,3$ glucan

(fungal extract)

SPR 901

$\alpha-1,6$ glucan

(Leuconostoc mesenteroides)

WSA

disaccharide bound to peptidoglycan

(M. smegmatis)

Table 6. Interrelationship of biological response modifiers to cytokines

Synthetic, biological, polysaccharides, herbs

$$
\begin{array}{cc}
\text { Primary cell receptors } \\
\text { Cytokine } \\
\downarrow \\
\downarrow & \downarrow \text { induction } \\
\text { Monocytes } & \text { Lymphocytes } \\
\text { (Monokines) } & \text { (Lymphokines) } \\
\downarrow & \downarrow \\
\text { Cytokines }
\end{array}
$$


Table 7. Characterization of biological response modifiers relative to cell regulated, cytokine and disease treatment

\section{Bacterial}

BCG

CR: $\uparrow$ T-cell function, macrophage (MPG), NK, CTL

CK: IL-1, IL-2, IFN- $\alpha, \mathrm{GM}-\mathrm{CSF}$, TNF $\alpha$

TR: + murine antitumour effect \pm adjuvant therapy; human recurrent superficial bladder tumours, transurethal resection and intravesical BCG leads to greater than $90 \%$ response, absence of recurrence.

OK432 (Pecibinil) Streptococcus pyogenes, strain A3

$\mathrm{CR}: \uparrow T$-cell function, MPG, NK, CTL, TIL

CK: IL-1, IL-2, IFN $\gamma$, TNF

TR: + murine antitumour; increase survival time and disease free interval in human colo-rectal, cervical, lung $\mathrm{Ca} ; \uparrow \mathrm{NK}$ MPG, T-cells in malignant ascites.

Lentinan (1,3, $\beta$-D-glucan; 1,6 - $\beta$-D-9-glucopyranosides), Lentinus edodes

CR: NK, MPG, T, bone marrow

CK: IL-2, IFN, CST

TR: + vs murine tumours, increase in ST, duration of remission of human CA, $\uparrow$ efficacy with chemical prophylactic vs influenza; Mesocestoides corti prophylactis.

$\mathrm{CR}=$ cell response $; \mathrm{CK}=$ cytokines $\mathrm{TR}=$ therapeutic response

production and induction of $\mathrm{TNF}-\alpha$ secretion from macrophages. ${ }^{7}$ Of particular interest is swainsonine's protective effect against bone marrow depression resulting from treatment with the chemotherapeutic agents methotrexate (M'TX), 5-fluorouracil (5-FU), cyclophosphamide (CP), or doxorubicin (DOX).

Thymosin fraction 5 (THF 5) when combined with thymosin alpha for the treatment of chronic hepatitis B led to clearance of the virus and improved liver function.

Table 8. Biological response modifiers of bacterial origin

\begin{tabular}{|c|c|c|c|}
\hline \multicolumn{4}{|c|}{ Bacterial extracts } \\
\hline $\begin{array}{l}\text { RU41740 } \\
\text { Klebsiella p } \\
\text { CR: T, MF } \\
\text { CK: IL-1, } \\
\text { TR: preve } \\
\text { FK 156, 50 } \\
\text { of Strepton } \\
\text { CR: T, NK } \\
\text { CK: IL-1, } \\
\text { TR: + mur }\end{array}$ & $\begin{array}{l}\text { (Biostim, N } \\
\text { neumonia } \\
\text { PG, NK, polyc } \\
\text { IL-6, GM-CS } \\
\text { nts bacterial r } \\
6,565 \text { : origin } \\
\text { nyces FK } 156 \\
\text {, MPG } \\
\text { CSF } \\
\text { ine tumours, }\end{array}$ & $\begin{array}{l}\text { PG) membrane } \\
\text { lonal B } \\
\text { espiratory infection } \\
\text { al } 156 \text { isolated fron } \\
565 \\
\text { antiviral (antibacte }\end{array}$ & protein extract \\
\hline $\begin{array}{l}\text { Treatment } \\
\text { Saline } \\
\text { FK565 }\end{array}$ & $\begin{array}{c}\text { Dose } \mu \mathrm{g} / \mathrm{kg} \\
-\overline{0} \\
0.01 \\
0.1 \\
1.0\end{array}$ & $\begin{array}{c}\text { NK Cytot. 100:1 } \\
10.1 \\
9.9 \\
34.3 \\
29.0\end{array}$ & $\begin{array}{c}\text { No. lung mets; B16 } \\
287 \\
307 \\
62 \\
9\end{array}$ \\
\hline
\end{tabular}

FK506: immunosuppressor: mechanism is considered to operate during the first signal transduction cascades and ultimately blocks the transcription of the genes that encode IL-2 and other lymphokines. Reported effective in treating psoriasis, organ rejection, nephrotic syndrome, Type 1 diabetes (insulindependent juvenile diabetes)

CR-cell response; $\mathrm{CK}=$ cytokines; $\mathrm{TR}=$ therapeutic response
Table 9. Biological response modifiers of thymus and various origin

Thymomodulin (TMD), thymolymphotropin (TLT), thymic derivatives containing several peptides

CR: NK, T, B, MPG

CK: IFN- $\gamma$, IL-2, BCGF, GM-CSF

TR: $\uparrow$ CD4 in AIDS; $120 \mathrm{mg} / \mathrm{kg} /$ day per o.s. for $30 \mathrm{~d}$ in acute type B hepatitis led to accelerated AST, ALT decrease, early HBs $\mathrm{Ag}$ clearance and normalization of elevated $\mathrm{cDg}$; a $50 \%$ sero conversion of pediatric $\mathrm{HBs} \mathrm{Ag}^{+} \mathrm{H}-\mathrm{Be} \mathrm{Ag}^{+}$chronic liver disease; and, protection vs bone marrow depression during intensive antitumour chemotherapy.

Betafectin-poly $1,6 \beta$-D-glucopyranosyl/1,3, $\beta$-D glucopyranose (glucose polymer); Saccharomyces cerevisiae RAD2.

CR: $\uparrow M P G, N K, B M$

CK: IL-1, IFN

TR: Protects vs E. coli peritoneal sepsis, Candida albicans, $S$. Aureus, lethal irradiation $\mathrm{LD}_{90}$. Mechanism binds to $\beta$-glucan receptors on Mo, PMN, which enhance phagocytic and microbicidal activity.

AM-3 - protein complexed B1,6, polyglucan, Candida utilis

CR: NK, T, MPG, bone marrow

CK: IL-1, IL-2, IFN $\alpha \beta$, CSF

TR: + vs murine tumour and viral infection; combined with chemotherapy led to earlier reconstitution of bone marrow, decrease in secondary infections.

$\mathrm{CR}=$ cell response $\mathrm{CK}=$ cytokines; $\mathrm{TR}=$ therapeutic response.

Another example of the similarity in responses achieved by BRMs and the cytokines they induce is shown in Table 12. Ampligen and CL246,738 are potent interferon inducers. Their antiviral effects were compared to recombinant IFN gamma $(\mathrm{rIFN}-\gamma)$ and $\mathrm{rIFN}-\alpha$ against four virus types. All four agents augmented NK cell activity as well as activating macrophages. An antiviral correlation was shown among all four against three of the four viruses.

Cytokines (Table 13) are increasingly recognized as essential and powerful cell communication and

Table 10. Biological response modifiers of various origin

\section{Synthetics}

Oxamisole-2,3,5,6,7,8 hexahydro - 2 - phenyl - 8,8 - dimethoxy imidazole $[1,2, \alpha]$ pyridine

CR: NK, ADCC

CK: IL-1, IL-2

TR: effective vs murine hepatitis (FB strain) decreased hepatic discoloration, SGOT, SGPT, virus titre in liver

Ampligen-mds RNA

CR: NK, MPG, CD4

CK: IFN $\alpha \beta$, CSF

TR: + vs murine tumours; inhibits AZT sensitive and resistant HIV-1, protects vs AZT bone marrow toxicity, increased CD4 count in treated AIDS patients.

HAB439-3 phenyl-2-isoxazoline-5-yl phosphoric acid

CR: T, NK

CK: not known

TR: may act through an aminopeptidase inhibitor; inhibits Listeria monocytogenes, Salmonella typhimurium, synergistic with ampicillin

$\mathrm{CR}=$ cell response $; \mathrm{CK}=$ cytokines $; \mathrm{TR}=$ therapeutic response. 
Table 11. Current applications of biological response modifiers

Swainsonine -indolizidine alkaloid

CR: NK, MPG, bone marrow

CK: IL-1, IL-2

TR: protects vs drug induced bone marrow suppression, LD $_{90}$ doses MTX, 5FU, CP, DOX combined with drug led to stimulation of bone marrow.

Thymosin-thymosin fraction $5+$ thymosin alpha 1 .

TR: treatment of chronic hepatitis B (phase II). Patients (20) enrolled; histological and biochemical evidence for active liver disease with + serum hepatitis B virus (HBV) DNA + hepatitis $B$ surface antigen (HBsAg). Rx, 2x/week, 6 months sc. At 1 year: $9 / 12$ thymosin treated and $2 / 8$ placebo showed norma serum alanine aminotransferase (ALT) and cleared (HBV) DNA from serum $(p<0.04)$. From twelve available pre- and post-treated liver biopsies; $4 / 5$ placebo and 1/7 thymosin $R x$ livers possessed replicative forms of (HBV) DNA.

$\mathrm{CR}=$ cell response $; \mathrm{CK}=$ cytokines $; \mathrm{TR}=$ therapeutic response

Table 12. Antiviral-in vivo responses

\begin{tabular}{lcccccc}
\hline BRM & NK & MPG & VEE & BANZI & HSV2 & Caraparu \\
\hline rIFN- $\gamma$ & + & + & + & - & + & NT \\
rIFN- $\alpha$ & + & + & + & + & + & NT \\
Ampligen & + & + & - & + & + & - \\
CL246,738 & + & + & + & + & + & + \\
\hline
\end{tabular}

VEE = Venezualen equine encephalitis (alpha toga virus)

BANZI (flavivirus); Caraparu (bunyavirus). + positive response; - no response; NT not tested.

regulatory molecules. They are implicated in normal homeostasis and defence against many diseases and are involved in the pathogenesis of a variety of disorders. As a result of their powerful and widespread regulatory functions, a number of cytokines are being tested as therapeutic agents (Table 14). At the same time, many antagonistic factors are being developed for use in those diseases that may be initiated or mediated by cytokines.
Table 14. Cytokines and their applications

EPO (Erythropietin). Regulates RBC production. Used for treating anaemia (reduces or eliminates blood transfusions in kidney dialysis patients, AIDS, cancer).

G-CSF (Granulocyte Colony Stimulating Factor). Stimulates granulocyte formation, adjuvant use to overcome leukopenia developing after chemotherapy.

GM-CSF (Granulocyte-Macrophage Colony Stimulating Factor). Stimulates production and function of activities of granulocytes and macrophages. Uses are similar to G-CSF.

IL-2 (Interleukin 2). Stimulates production and function of T-cells, NK cells. Use in treating renal cell carcinoma, melanoma. Potential synergy with alpha IFN; uses in infection and vaccine adjuvant.

Alpha Interferon. Approved in 50 countries for 16 indications including cancer, AIDS, hepatitis.

Beta Interferon. Similar clinical properties to alpha-IFN. Being tested for viral diseases and multiple sclerosis.

Gamma Interferon. Potential uses in cancer, infectious diseases, ectopic dermatitis, rheumatoid arthritis.

TNF (tumour necrosis factor). rTNF used in limited clinical trials as potential anti-cancer agent.

The field of cytokine biology is growing rapidly. Studies are being conducted that embrace analysis of molecular regulation of cytokine expression through the use of cytokines per se as therapeutic agents. Diseases that involve employing cytokines include cancer, infectious diseases, inflammatory processes, autoimmune disorders, physiological development defects, and ageing. Cytokines appear to extend in some fashion to every organ system of the body. Of particular interest is the potential use of cytokines in the treatment of cancer, where they are being tested as direct antitumour agents, as enhancers of various cellular components of the immune system reactive against tumour cells, as potentiators of chemotherapy and radiotherapy, and as protective agents against the myelotoxicity

Table 13. Cytokines derived from monocytes/macrophages (monokines) or lymphocytes (lymphokines)

\begin{tabular}{lll}
\hline Cytokine & \multicolumn{1}{c}{ Primary cell source } \\
\hline IL-1 & $\begin{array}{l}\text { Macrophages, keratinocytes, } \\
\text { endothelial cells, fibroblasts, T, B }\end{array}$ & \multicolumn{1}{c}{ Primary effects } \\
IL-2 & T-lymphocytes and LGL & Activates T- and NK cells \\
IL-3 & T-lymphocytes & Promotes myeloid progenitor cells \\
IL-4 & Th cells & T-, B-cell growth factor, promotes IgE \\
IL-5 & Th cells & Stimulates B-cells, eosinophils \\
IL-6 & Fibroblasts, other & Growth factor B-cells, polyclonal IG \\
IL-7 & Stromal cells & Lymphopoietin, generates pre-B, T \\
IL-8 & Macrophages, other & Regulates lymphocyte, neutrophils, homing, infiltration, chemo attracts \\
G-CSF & Monocytes, other & Myeloid growth factor, generates neutrophils \\
M-CSF & Monocytes, other & Macrophage growth factor, macrophages \\
GM-CSF & T-cells, other & Monomyelocytic GF, myelopoiesis \\
IFN- $\alpha$ & Leucocytes & Stimulates macrophages and NK cells \\
IFN- $\beta$ & Fibroblasts & Stimulates macrophages and NK cells \\
IFN- $\gamma$ & T-and NK cells & Induces cell membrane Ag (MHC) \\
TNF $\alpha$ & Macrophages, other & Vascular thromboses, tumour necrosis \\
TNF $\beta-$-LT & T-lymphocytes & and inflammatory, immunoenhancer \\
TNF $\beta$ & Platelets, bone, other & Wound healing, bone remodelling, fibroplasia, immunosuppressor \\
\hline
\end{tabular}


Table 15. Mediators of natural immunity

\begin{tabular}{|c|c|c|c|}
\hline Cytokine & Cell source & Cell target & Primary effects \\
\hline Type 1 IFN & Mononuclear phagocyte (a), fibroblast (b) & All & $\begin{array}{l}\text { Antiviral, } \\
\text { antiproliferative; } \\
\text { increases class I } \\
\text { MHC expression }\end{array}$ \\
\hline Tumour necrosis factor 1 & Mononuclear phagocyte, T-cell & $\begin{array}{l}\text { Neutrophil, } \\
\text { endothelial, } \\
\text { hypothalamus, } \\
\text { liver, muscle, } \\
\text { fat, T-cell, B-cell }\end{array}$ & $\begin{array}{l}\text { Activation } \\
\text { (inflammation), } \\
\text { activation } \\
\text { (coagulation), } \\
\text { fever, acute phase } \\
\text { reactants, } \\
\text { catabolism } \\
\text { (cachexia), } \\
\text { costimulator }\end{array}$ \\
\hline Interleukin 1 & Mononuclear phagocyte, other & $\begin{array}{l}\text { T-cell, B-cell, } \\
\text { endothelial cell, } \\
\text { hypothalamus, } \\
\text { liver, muscle, fat }\end{array}$ & $\begin{array}{l}\text { Costimulator, } \\
\text { antiviral } \\
\text { (inflammation, } \\
\text { coagulation), } \\
\text { fever, acute } \\
\text { phase reactants, } \\
\text { catabolism } \\
\text { (cachexia) }\end{array}$ \\
\hline Interleukin 6 & Mononuclear phagocytes, T-cell, endothelial cell & $\begin{array}{l}\text { T-cell, B-cell, } \\
\text { mature B-cell, } \\
\text { liver }\end{array}$ & $\begin{array}{l}\text { Costimulator, } \\
\text { growth, acute } \\
\text { phase reactants }\end{array}$ \\
\hline MIP-1 & Mononuclear phagocytes & $\begin{array}{l}\text { Neutrophils, } \\
\text { macrophages, } \\
\text { hypothalamus }\end{array}$ & $\begin{array}{l}\text { Costimulator, } \\
\text { activation. } \\
\text { (inflammation), } \\
\text { costimulator } \\
\text { (induced TNF } \alpha \text { ) } \\
\text { IL-1, IL-6 } \\
\text { production), } \\
\text { fever }\end{array}$ \\
\hline
\end{tabular}

associated with current cancer treatments. In contrast to their potential therapeutic value, some cancer cells produce cytokines which may be involved in autocrine growth stimulation.

Cytokines have been classified into four categories:

(1) Mediators of natural immunity consisting of Type 1 IFN, TNF, IL-1, IL-6, and low molecular weight inflammatory cytokines to which the recently reported MIP-1 may belong. ${ }^{8}$

(2) Mediators of lymphocyte activation, growth, and differentiation consisting of IL-2, IL-4 and transforming growth factor beta (TGF- $\beta$ ).

(3) Mediators of effector cell activation consisting of IFN- $\gamma$, lymphotoxin, IL-5, and migration inhibition factor (MIF).

(4) Mediators of immature leucocyte growth and differentiation consisting of IL-3, GM-CSF, $\mathrm{M}-\mathrm{CSF}, \mathrm{G}-\mathrm{CSF}$, and IL-7.

Mediators of natural immunity are the host's more initial and immediate responders since they initiate protection against viral infection. They initiate inflammatory reactions that protect against bacteria (Table 15). In some cases this complex defence network successfully restores normal homeostasis and health, but at other times the overproduction of immunoregulatory mediators may actually prove deleterious to the host. Some examples of immune system mediated injury have been extensively investigated including anaphylactic shock, autoimmune disease, and immune complex disorders. More recently it has become clear that the cytokine TNF occupies a key role in the pathophysiology associated with diverse inflammatory states and other serious illnesses including septic shock. TNF exhibits beneficial and deleterious functions when combined with adriamycin. ${ }^{9}$ TNF demonstrated an enhanced cytotoxicity against several adriamycin resistant human tumour lines. A similar synergistic enhancement of adriamycin cytotoxicity against human osteosarcoma cells by TNF- $\alpha$ was also reported. ${ }^{10}$

In contrast, several reports indicate that $\mathrm{TNF}$ also possesses deleterious properties. Recombinant TNF functioned as an autocrine growth factor which enhanced growth of four human neuroblastoma cell lines. ${ }^{11}$ Blocking factors (soluble receptors) for human TNF and lymphotoxin (LT) were found in the serum, cerebral spinal fluid, and tumour cyst fluid (TCF) of human glioma tumour patients. ${ }^{12}$ The presence of these receptors would abrogate any tumour cytolytic activity of TNF or 
Table 17. Potential treatments for septic, shock

\section{Early attempts}

1980s Treatment with human antisera to $E$. coli J5, a mutant strain producing LPS with variable oligosaccharide. Of 212 bacteraemic patients treated $50 \%$ survived.

Drawbacks to antiserum - heterologous pool of sera, standardization difficulty, serum contaminated with infectious agents.

1985 Monoclonal immunoglobulin $M(\lg M)$ binding specifically to the lipid A domain of LPS. Comparative study

1. Standard therapy and antibiotics and fluids, $49 \%$ died.

2. Standard therapy and m/Ab to lipid A, 30\% died.

\section{0s}

1. IL-1 ra (IL-1 receptor antagonist). Natural protein antagonist of IL-1, competes for IL-1 receptor (Antril).

2. IL-1r (interleukin 1 receptor). Competes with the natural $\mathrm{IL}-1$ receptor to down-regulate $\mathrm{IL}-1$.

3. Anti-TNF mAb (antitumour necrosis factor antibody) Blocks TNF mediated damage in sepsis, cachexia, etc.

4. TNF inhibitors (tumour necrosis factor inhibitors). Natural protein inhibitors of TNF that might limit systemic damage in septic shock.

5. TNFr-Fc (TNF receptor immunoadhesion). Soluble TNFr linked to $\mathrm{Fc}$ region of $\mathrm{m} \cdot \mathrm{Ab}$. Potential use in sepsis.

6. Sepsis mAb. Monoclonal antibodies vs Gram-negative bacterial endotoxin for treatment of sepsis syndrome and septic shock.

7. BPI (bacterial permeability increasing protein). Neutrophil granule protein, blocks Gram-negative endotoxin; inhibits TNF, IL-6 and IL-8 cytokines.

8. Other drugs: pentoxiphylline; L-carnitine derivatives.

LT. Similar TNF growth promoting activities were reported for ovarian cancer ${ }^{13}$ and perhaps for mammary tumour cells. ${ }^{14}$ Colony growth of leukaemic colony-forming units (L-CFU) obtained from patients with primary acute myelogenous leukaemia stimulated with recombinant human IL-3 (rhIL-3) was reported to be significantly potentiated when recombinant human TNF- $\alpha$ was present in the culture. ${ }^{15}$ Studies on the mechanism of action of rhTNF- $\alpha$ on the acute myelogenous leukaemia L-CFU growth suggests that TNF- $\alpha$ acts by inducing release of growth stimulating haematopoietic cytokines by the leukaemic cells themselves including IL-1 $\alpha$, IL- $1 \beta$, GM-CSF, G-CSF, and IL-6. Treatment with neutralizing antibody to all of the above cytokines significantly inhibited the synergistic interplay of TNF- $\alpha$ and IL-3. The role of TNF leading to septic shock is illustrated in Table 16.

Advances in cytokinology and molecular biology develop in such a way that multiple approaches emerge to attack a problem. That has happened for septic shock, a frequently fatal reaction following bacterial infection leading to a bacteraemia. Using recent advances in cytokine biology and recombinant DNA technology immunologists and molecular biologists are currently evaluating six potential new treatments for septic shock. ${ }^{16}$

Investigators who study septic shock fall into two categories (Table 17). One group works to
Table 16. Tumour necrosis factor leading to septic shock

The most prominent bacterial infections are $E$. coli, $P$. aeruginosa, Klebsiella and Bacteroides. When these are present in blood (bacterial sepsis), levels of TNF increase, and autocrine and paracrine effects increase IL-1 and IL-6. The combined effect

1 Leads to depressed myocardial contractility (reduces tissue perfusion)

2 Relaxes vascular smooth muscle tone (leads to a reduction of blood pressure and tissue perfusion).

3 Causes intravascular thrombosis.

4 Causes severe metabolic disturbances (life threatening fall in blood glucose concentrations).

5 Leads to a spontaneous clotting in blood vessels, severe hypotension, multiple organ damage (mostly due to circulatory collapse and oxygen free-radical damage).

The rate of occurrence of septic shock following septicaemia is 175 per 100000 people yearly, and 500 per 100000 for patients in hospitals. Of those that develop septic shock, 25 to $40 \%$ die.

interrupt the cytokine mediated immune response to septicaemia, while the other group targets LPS, either to neutralize it in the blood or to prevent it from activating leucocytes that start the inflammatory response. The latter approach however would function for Gram-negative sepsis only.

\section{References}

1. Chirigos MA, Talmadge JE. Immunotherapeutic agents: their role in cellular immunity and their therapeutic potential. Springer Semin Immunopathol $1985 ; 8: 327-346$

2. Talmadge JE, Chirigos MA. Comparison of immunoregulatory and immunotherapeutic properties of biological response modifiers. Semin Immunopathol 1985; 8: 429-443

3. Velotti F, Cippitelli M, Palmieri $\mathrm{G}$ et al. In vitro bladder cancer cells express interleukin 2 receptor. A ACR Proceedings 1992; 33: 301.

4. Chirigos MA. Immunomodulators: current and future development and applications. Thymus 1992; Suppl 1: S7-S20.

5. Ishida N, Hoshino TA. Streptococcal preparation as a potent biological response modifier (OK432). Exerpta Medicus (second edn) 1985; 1-69.

6. Chirigos MA, Saito T, Talmadge JE, Budzynski W, Gruys E. Cell regulatory and immunorestorative activity of Ricibanil (OK432). Cancer Detect Prevent Suppl 1987; 1: 317-320.

7. Gryegorgewski K, Breton P, White S, Olden K. Effect of swainsonine on murine peritoneal macrophages in vitro superoxide radical production, phagocytosis, kinetics of activation, and TNF alpha production. $A A C R$ Proceedings 1992; 33: 304

8. Sherry B. The role of cytokines in the regulation of cell function and in the pathogenesis of disease: a pathology A-B study section workshop. Cancer Res 1992; 52: 6129-6133.

9. Safrit J'T, Bonavida B. Sensitivity of resistant human tumor lines to tumor necrosis factor and adriamycin used in combination: correlation between down regulation of tumor necrosis factor messenger RNA induction and overcoming resistance. Cancer Res 1992; 52: 6630-6637.

10. Jia SF, Fara D, Kleinerman ES. Synergistic enhancement of adriamycin cytotoxicity against human osteosarcoma cells by TNF- $\alpha$. AACR Proceeding. 1992; 33: 552.

11. Goillot E, Combaret V, Landenstein $\mathrm{R}$ et al. Tumor necrosis factor (TNF) as an autocrine growth factor for neuroblastomas. AACR Proceedings 1992; 33: 346 .

12. Ioli G, Yamamoto R, Jacques D et al. Blocking factors (soluble receptors) for human TNF and IT in the serum, cerebrospinal fluid (CSF), and tumor cyst fluid (TCF) of human glioma patients. A ACR Proceedings 1992; 33: 309 .

13. Naylor MS, Stamp GW, Foulkes W et al. TNF (tumor necrosis factor). A role in ovarian cancer? AACR Proceedings 1992; 33: 262.

14. Tsai SJ, Miller J, Wei WZ et al. Tumor necrosis factor (TNF) modulate growth of normal and neoplastic murine mammary cells. AACR Proceeding 1992; 33: 269.

15. Brock MA, Gruss HJ, Asano Y et al. Synergy of interleukin 3 and tumo necrosis factor alpha in stimulating clonal growth of acute myelogenous leukemia blasts is the result of induction of secondary hematopoietic cytokines by tumor necrosis factor alpha. Cancer Res 1992; 52: 6129-6133.

16. Johnston J. Molecular science gets its sights on septic shock. J NIH Research $1991 ; 3(10): 61-65$ 


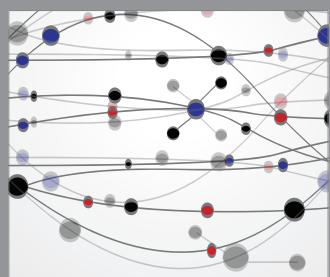

The Scientific World Journal
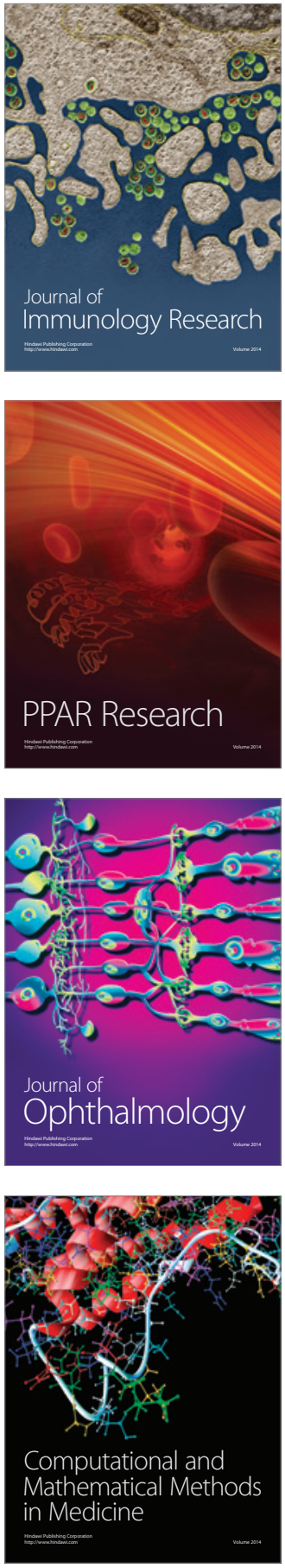

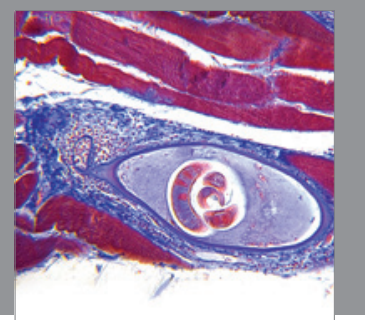

Gastroenterology

Research and Practice
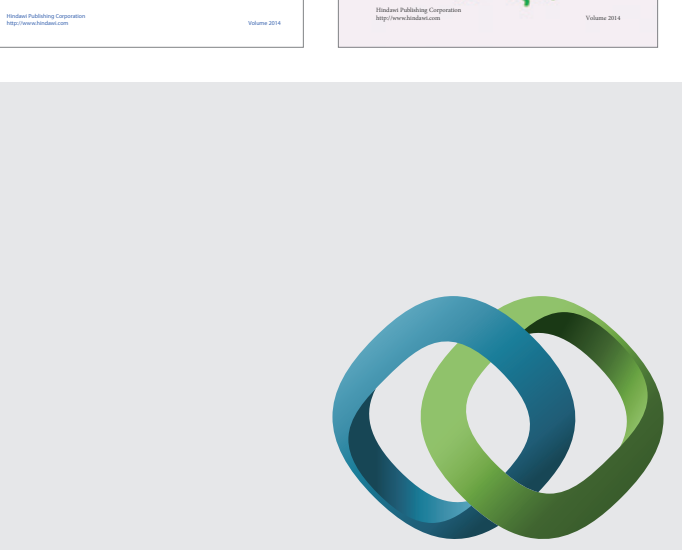

\section{Hindawi}

Submit your manuscripts at

http://www.hindawi.com
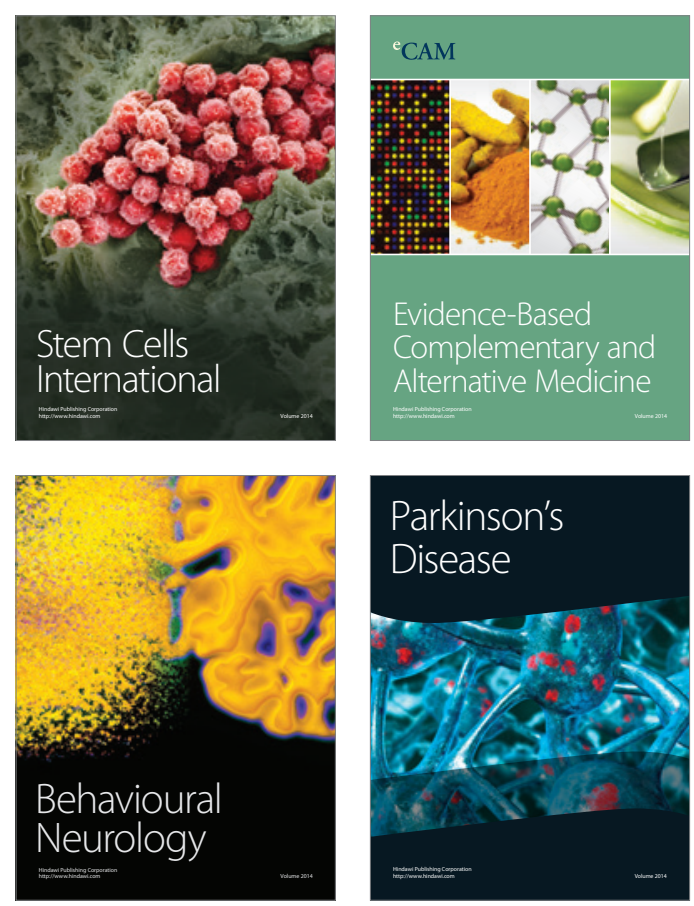

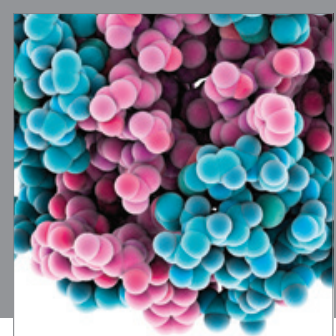

Journal of
Diabetes Research

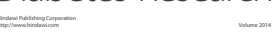

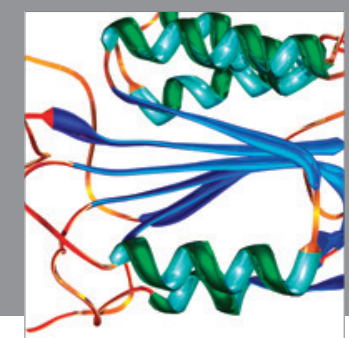

Disease Markers
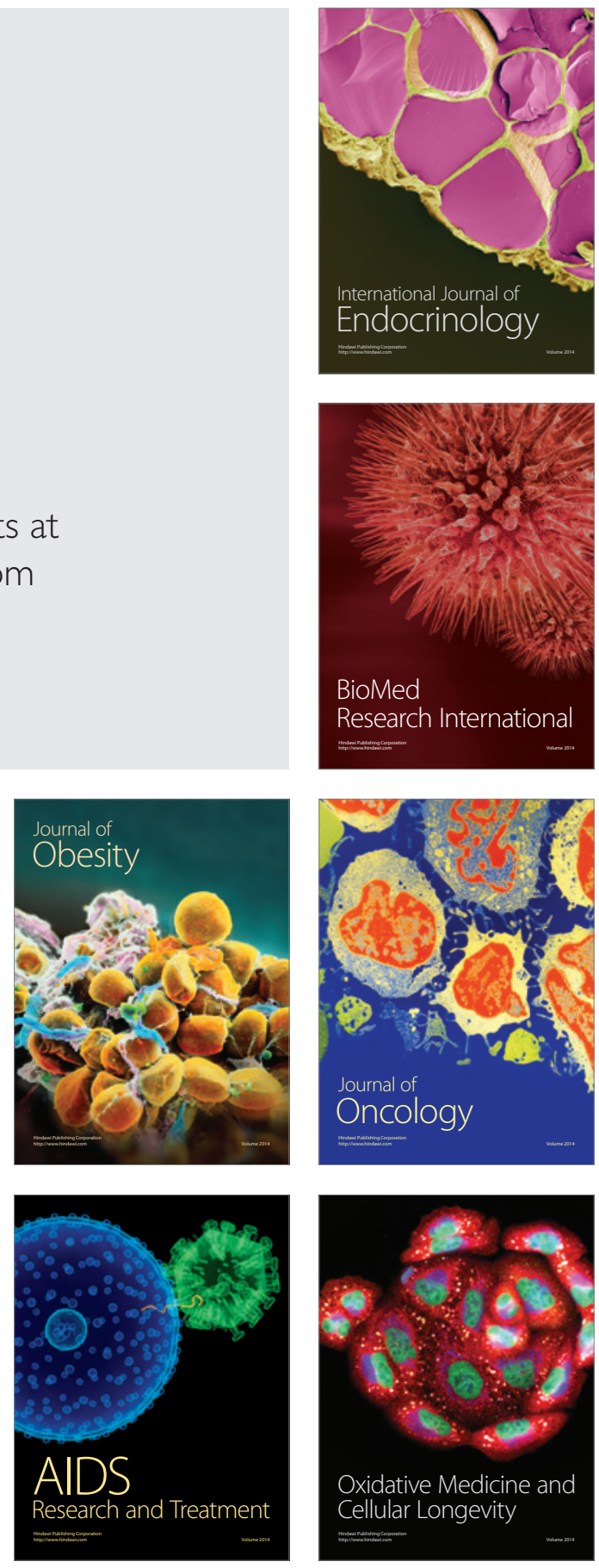